Journal of Ophthalmology

Elsevier Editorial System(tm) for American

Manuscript Draft

Manuscript Number: AJO-18-500R2

Title: Macular pigment distribution as prognostic marker for disease progression in macular telangiectasia type 2

Article Type: Original Article

Keywords: Macular telangiectasia type 2; MacTel type 2; Macular pigment optical density; Predicitive parameter; Biomarker; Ellipsoid zone;

Paracentral scotoma

Corresponding Author: Dr. Simone Müller, M.D.

Corresponding Author's Institution: University Hospital of Bonn

First Author: Simone Müller, M.D.

Order of Authors: Simone Müller, M.D.; Peter Charbel Issa; Tjebo F.C.

Heeren; Sarah Thiele; Frank G. Holz; Philipp Herrmann 
Müller et al.: Macular pigment distribution and disease progression in MacTel type 2

Purpose: To evaluate macular pigment distribution pattern as a prognostic marker for disease progression in patients with macular telangiectasia type 2 (MacTel).

Design: Retrospective cohort study

Methods: In this single-center study, 90 eyes of 47 patients were analyzed. Macular pigment optical density (MPOD) was measured with dual wavelength fundus autofluorescence. Eyes were graded into MPOD distribution classes 1 to 3 with increasing loss of macular pigment and grading was performed blinded by two independent graders. Best corrected visual acuity, reading acuity, total scotoma size in fundus-controlled perimetry (microperimetry) and break of the ellipsoid zone (EZ) in optical coherence tomography (en face measurement) were defined as functional and morphologic outcome parameters and evaluated at baseline and after 60 months.

Results: After a mean review period of 59.6 months ( \pm SD 5.2 months), no change between MPOD classes was observed compared to baseline. Morphologic and functional deficits were limited to the area of MPOD loss. At follow up, a significant mean decrease of visual acuity and reading acuity as well as a significant mean increase of scotoma size and EZ break was observed in eyes assigned to MPOD classes 2 and 3 , while outcome parameters remained stable in eyes of class 1 .

Conclusions: The results indicate that MPOD and its distribution may serve as a prognostic marker for disease progression and functional impairment in patients with MacTel. 
*Manuscript (incl. title, auth, corr.auth., demographics, references, legend)

Müller et al.: Macular pigment and disease progression in MacTel type 2

\section{Macular pigment distribution as prognostic marker for disease progression in macular telangiectasia type 2}

Simone Müller, $\mathrm{MD}^{1^{*}}$, Peter Charbel Issa, MD, DPhil ${ }^{4}$, Tjebo F.C. Heeren, MD ${ }^{2,3}$, Sarah Thiele, $\mathrm{MD}^{1}$, Frank G. Holz, MD ${ }^{1}$, Philipp Herrmann, MD, $\mathrm{PhD}^{1}$
Department of Ophthalmology, University of Bonn, Bonn, Germany Moorfields Eye Hospital NHS Foundation Trust, London, UK University College London, Institute of Ophthalmology, London, UK
Oxford Eye Hospital, Oxford University Hospitals NHS Foundation Trust, and Nuffield Laboratory of Ophthalmology, Department of Clinical Neurosciences, University of Oxford, Oxford, UK

Conflict of Interest: None of the authors has a proprietary interest in this work.

Short title: Macular pigment and disease progression in MacTel type 2

Supplemental Material available at AJO.com.

* Corresponding author:

Simone Müller, MD

Department of Ophthalmology, University of Bonn

Ernst-Abbe-Str. 2, 53127 Bonn, Germany

E-Mail: simone.mueller@ukbonn.de

Tel.: +49 228-287-13253 
Müller et al.: Macular pigment and disease progression in MacTel type 2

Macular telangiectasia (MacTel) type 2 is a bilateral macular disease with structural and functional changes that affect an oval-shaped area of approximately $6^{\circ}$ horizontal and $5^{\circ}$ vertical diameter that is centered on the fovea. Based on phenotypic findings, MacTel is believed to be a slowly progressive neurodegenerative disease with additional vascular alterations. Characteristic findings in funduscopy and multimodal imaging have been reported previously. ${ }^{1-3}$ Symptoms include reading difficulties and metamorphopsia ${ }^{4-6}$ while distance visual acuity is usually affected later in the disease course..$^{2,4,7}$ Reading difficulties were proposed to be associated with paracentral scotomata that can be detected by fundus controlled perimetry (microperimetry). ${ }^{2,4,8}$ Microperimetry enables a precise examination of position, size and depth of central and paracentral scotomata and displays a good functional correlation to morphological changes in MacTel. ${ }^{79-11}$

Patients with MacTel type 2 show a characteristic depletion of macular pigment. ${ }^{12-15}$ Several functions have been proposed for macular pigment, including filtration of blue light, ${ }^{16-18}$ reduction of glare and photic damage, and, on a molecular level, neuroprotection of retinal cells. ${ }^{19-21}$

Zeimer et al. suggested a classification system consisting of three different patterns of macular pigment distribution in MacTel (Figure 1). ${ }^{22}$ An association between visual acuity / disease stage and MPOD classes has previously been shown. However, the prognostic value of MPOD classes for functional outcome has not yet been investigated. In our experience, MPOD distribution patterns seem to be a very stable clinical parameter in patients with MacTel. We therefore sought to determine the change in MPOD classes over time and hypothesized that this pattern may be of predictive value for functional and structural disease progression. 
Müller et al.: Macular pigment and disease progression in MacTel type 2

\section{Methods}

In this retrospective, longitudinal analysis, participants were selected from the Natural History and Observation Study (NHOS) from a single center cohort at the Department of Ophthalmology, University of Bonn, Germany. Protocol details of the study have been published previously ${ }^{24}$. The diagnosis of MacTel type 2 was based on characteristic morphologic findings in funduscopy, spectral domain optical coherence tomography (SD-OCT), macular pigment optical density (MPOD), and fluorescein angiography. ${ }^{1}$ The study was approved by the Ethics Committee of the University of Bonn (consecutive number 347/17), and was in adherence to the tenets of the Declaration of Helsinki. All participants provided informed consent.

Patients underwent annual follow up examinations including best-corrected visual acuity (BCVA) testing, reading acuity testing, SD-OCT and dilated funduscopy. Additionally to the standard protocol, fundus controlled microperimetry was performed on both eyes (MP1, Nidek Technologies, Padua, Italy) as described previously ${ }^{2}$. A central test grid with 45 test stimuli (Goldmann size III, 4-2 strategy, $1.27 \mathrm{~cd} / \mathrm{m}^{2}$ background illumination, stimulation time $100 \mathrm{~ms}$, also see figure 3 ) centered on the fovea with a stimulus intensity ranging from 0 to $20 \mathrm{~dB}$ was applied. Based on the findings of test-retest measurements by Chen et al. ${ }^{25,26}$, depth of scotomata was categorized into absolute ( $A$ : defined by retinal sensitivity of $<0 \mathrm{~dB}$ ) and relative ( $R$ : retinal sensitivity $\geq 0$ to $\leq 12 \mathrm{~dB}$ ). Scotoma size was determined as previously described. ${ }^{10}$ In brief, as previous work showed a good correspondence of ellipsoid zone (EZ) break (en face) in SD-OCT and sensitivity reduction in microperimetry, a direct alignment of the results was omitted, but single test points with a reduction of sensitivity of $\leq 12 \mathrm{~dB}$ were counted within the tested area and the total sum of these points was defined as scotoma size. 
Müller et al.: Macular pigment and disease progression in MacTel type 2

Inclusion criteria for this study were a clinical diagnosis of MacTel, a full data set including the above mentioned examinations at baseline and at 60 months after baseline. Exclusion criteria were the presence or development of secondary neovascularizations at baseline or during the observational period.

For measurement of the ellipsoid zone break, high density SD-OCT volume scans (97 B-scans, $15^{\circ}$ horizontal x $10^{\circ}$ vertical; Spectralis, Heidelberg Engineering, Heidelberg, Germany) were evaluated using the 3D view panel for en face visualization of the EZ layer as described elsewhere. ${ }^{10}$ Manual correction of segmentation and of the position of the en face overlay and its correspondence to the zone of EZ break, was applied as needed.

Distribution of MPOD was evaluated as described previously using a modified twowavelengths Heidelberg Retina Angiograph (Heidelberg Engineering, Heidelberg, Germany). ${ }^{14,27}$ In short, MPOD was measured from two averaged fundus autofluorescence images, that were calculated from two movies (minimum of 4 seconds), that were obtained at two different excitation wavelengths of $488 \mathrm{~nm}$ and $514 \mathrm{~nm}$, in combination with a barrier filter, that blocks all wavelengths $<560 \mathrm{~nm}$. Images were analyzed at baseline and 60 months after baseline, and eyes were subsequently graded and assigned to MPOD classes 1 to 3 (see above, figure 1). Grading was performed blinded by two independent graders (MS and TS).

Reading acuity was tested monocularly using Radner reading test as described previously. ${ }^{4}$ Reading was performed at a test distance of $40 \mathrm{~cm}$ and with best corrected refraction for this distance.

Statistical analyses were performed using GraphPad Prism version 7.0 (GraphPad Software, San Diego, CA, USA). Continuous variables were described by using the 
Müller et al.: Macular pigment and disease progression in MacTel type 2

mean \pm standard deviation and categorical variables were analyzed using frequency tables. Change variables were standardized to change per year and change measures $(\Delta)$ were conducted as follows: (follow up measurement - baseline measurement)/time between measurements [months/12]. For intergroup comparisons unpaired t-test with Welch`s correction and Mann-Whitney-test were computed, respectively. Inter-observer agreement was calculated using Cohen`s kappa $(\kappa)$ test. A p-value $<0.05$ was accepted as statistically significant.

\section{Results}

Data of 90 eyes (47 patients; mean age of 61.7 years ( \pm SD 6.4; range: $52-78)$ ) were analyzed at baseline and 59.6 months ( \pm SD 5.2 months, follow-up (FU)) after baseline.

According to the distribution of macular pigment at baseline, 18 eyes were assigned to MPOD class 1,23 eyes to class 2 and 49 eyes to class 3.29 out of 47 patients (61.7\%) had symmetrical distribution patterns in both eyes, while 18 patients $(38.3 \%)$ showed asymmetrical distribution patterns in the right and the left eye. There were no significant differences in age or gender between the subgroups. Baseline characteristics of all eyes are shown in the table. During the entire observational period, no switch in MPOD classes was observed (examples shown in supplementary figure 1). The strength of inter-observer agreement was high $(\mathrm{k}=0.86)$. In all eyes, overlays of MPOD maps and en face OCT images (figure 2) revealed a limitation of EZ loss and its progression to the area of reduced MPOD. Similarly, formation and growth of scotomata, as observed on microperimetry testing, were limited to areas with depleted MPOD. Exemplary courses of the EZ loss (en face) 
Müller et al.: Macular pigment and disease progression in MacTel type 2

and scotoma growth, respectively, of three MacTel eyes assigned to MPOD classes 1 to 3 are shown in figure 2 and 3.

Morphologic and functional outcome parameters after 60 months compared to baseline

Over the entire observational period, eyes with class 1 MPOD distribution showed a stable visual acuity and only slight loss of reading acuity. In contrast, eyes of MPOD classes 2 and 3 experienced a significant mean loss of VA (-0.16 logMAR \pm SD 0.08 and $0.20 \log M A R \pm S D 0.14$, respectively) and reading acuity $(0.22 \log R A D \pm S D 0.13$ and $0.26 \log R A D \pm S D 0.16$, respectively) compared to baseline (figure 4- top left and right).

Growth of ellipsoid zone defects and scotomata was significantly higher in eyes of classes 2 and 3 compared to eyes of class 1 (both $p<0.0001$ ). At last follow up, all 72 eyes of classes 2 and 3 showed an increase and/or de novo formation of EZ break in OCT and scotomata in microperimetry. Out of the 18 eyes with class 1 MPOD distribution, only six eyes (33\%) showed a loss of EZ and a growth (4/6) or de novo formation $(2 / 6)$ of scotomata within the observational period. Intergroup comparisons of both functional and morphologic parameters indicated that eyes with class 1 differed from those with class 2 and 3, the latter showing marked similarities. Thus, loss of foveal pigment at baseline was associated with future functional loss.

\section{Discussion}

In this study, we demonstrated that the distribution ('class') of MPOD is a predominantly stable parameter over several years. We showed that areas of reduced MPOD are associated with the extent and expansion of forthcoming neurodegenerative changes, and thus future functional deficits. 
Müller et al.: Macular pigment and disease progression in MacTel type 2

Several functions have been proposed for macular pigment, including

neuroprotective properties, filtering harmful short-wavelength-lights and acting as powerful scavenger of reactive oxygen species. ${ }^{17-21}$ Depletion of macular pigment is a characteristic finding in MacTel ${ }^{12-15}$ and different associations of morphologic and functional changes with areas of depleted MPOD have been described. ${ }^{13}$

Different explanations for the abnormal patterns of pigment distribution in MacTel have been discussed: The depletion of macular pigment may result from structural alterations in the central retina, e.g. a dysfunction or loss of Müller cells. Histological findings in eyes affected by MacTel revealed that the loss of macular pigment coincided with a dysfunction or loss of Müller cells in the macular region, corroborating the understanding of MacTel as a potential Müller cell disease.$^{28}$ Müller cells exhibit a multitude of functional interactions with neurons. They help to process visual information and to preserve the blood-retina barrier ${ }^{29-31}$ and they have neuroprotective properties. ${ }^{30,32,33}$

A dysfunction or loss of Müller cells may lead to an impaired storage and trafficking of macular pigment, and the absence of neuroprotective properties of MPOD/ Müller cells may subsequently constitute the basis for further (neurodegenerative) changes. This may explain why we observed neurodegenerative changes to occur and expand only in regions with preexisting pigment loss, while areas with intact pigment distribution remained unaffected.

The data from our study is in line with previous findings: Though, in a longitudinal setup, Zeimer et al. noted a slowly-progressive, quantitatively measurable loss of macular pigment, that expanded mainly in a horizontal direction ${ }^{23}$, a consecutive, longitudinal change of MPOD classes over time was not presented. Vice versa, a longitudinal study including the systemic supplementation with lutein and zeaxanthin 7 
Müller et al.: Macular pigment and disease progression in MacTel type 2

was shown to enrich MPOD in regions with preserved macular pigment, but not in regions, where MPOD was already depleted. ${ }^{22,34,35}$ Again, a switch from one class to another was not shown, indicating the distribution and unique depletion of MPOD to be a predominantly stable parameter over time in MacTel. However, MacTel is a very slowly progressive disease, and we thus cannot exclude that the absence of a conversion between different MPOD classes might be ascribed to the limited observational period of 5 years.

In line with Zeimer et al., who observed an association of increasing MPOD classes with decreasing visual function and increasing disease stages according to Gass and Blodi in a cross-sectional study, ${ }^{36}$ we noted worse functional outcome and extended disease progression with higher MPOD classes (and thus decreasing MPOD) over time. MPOD classes $2 / 3$ differ from class 1 per definition by a loss of the foveal pigment peak. Considering the known neuroprotective properties of macular pigment, we assume that foveal macular pigment loss entails foveal involvement and may thus forecast a worse functional outcome in these eyes.

We hence interpreted our findings not as a direct correlation between loss of MPOD and loss of function, as has been proposed previously, but as a correlation between MPOD distribution patterns and forthcoming disease progression.

Study limitations: The observational period in this study was limited to 60 months. Long-term studies beyond this period are needed in order to verify our results. In this study, our findings were based on qualitative grading of macular pigment distribution into MPOD classes. Additional quantitative measurements might help to predict the progression of the disease even more precisely and are thus warranted for future studies. 
Müller et al.: Macular pigment and disease progression in MacTel type 2

\section{Conclusions}

The results indicate that MPOD and its patterns of distribution may help to predict future disease progression and functional loss over the course of several years in patients with MacTel. This would allow for a better evaluation of the disease progression and individual functional outcome, and thus for a more appropriate consultation of affected patients.

\section{Acknowledgements/ Disclosure:}

\section{No financial disclosures.}

Support: This work was supported by the Lowy Medical Research Institute, La Jolla, USA; ProRetina, Bonn, Germany and the National Institute for Health Research (NIHR) Oxford Biomedical Research Centre (BRC), Oxford, UK. 


\section{References}

1. Charbel Issa P, Gillies MC, Chew EY, et al. Macular telangiectasia type 2. Prog Retin Eye Res. 2013;34:49-77.

2. Charbel Issa P, Helb HM, Rohrschneider K, Holz FG, Scholl HP. Microperimetric assessment of patients with type 2 idiopathic macular telangiectasia. Invest Ophthalmol Vis Sci. 2007;48(8):3788-3795.

3. Barthelmes D, Gillies MC, Sutter FK. Quantitative OCT analysis of idiopathic perifoveal telangiectasia. Invest Ophthalmol Vis Sci. 2008;49(5):2156-2162.

4. Finger RP, Charbel Issa P, Fimmers R, Holz FG, Rubin GS, Scholl HP. Reading performance is reduced by parafoveal scotomas in patients with macular telangiectasia type 2 . Invest Ophthalmol Vis Sci. 2009;50(3):1366-1370.

5. Charbel Issa P, Holz FG, Scholl HP. Metamorphopsia in patients with macular telangiectasia type 2. Doc Ophthalmol. 2009;119(2):133-140.

6. Heeren TF, Holz FG, Charbel Issa P. First symptoms and their age of onset in macular telangiectasia type 2. Retina. 2014;34(5):916-919.

7. Heeren TF, Clemons T, Scholl HP, Bird AC, Holz FG, Charbel Issa P. Progression of Vision Loss in Macular Telangiectasia Type 2. Invest Ophthalmol Vis Sci. 2015;56(6):3905-3912.

8. Trauzettel-Klosinski S. Reading disorders due to visual field defects: a neuroophthalmological view. Neuro-Ophthalmology. 2002;27(1-3):79-90.

9. Sallo FB, Leung I, Mathenge W, et al. The prevalence of type 2 idiopathic macular telangiectasia in two African populations. Ophthalmic Epidemiol. 2012;19(4):185-189.

10. Heeren TFC, Kitka D, Florea D, et al. Longitudinal correlation of ellipsoid zone loss and functional loss in macular telangiectasia type 2. Retina. 2017.

11. Charbel Issa P, Troeger E, Finger R, Holz FG, Wilke R, Scholl HP. Structure-function correlation of the human central retina. PLoS One. 2010;5(9):e12864.

12. Helb HM, Charbel Issa P, RL VDV, Berendschot TT, Scholl HP, Holz FG. Abnormal macular pigment distribution in type 2 idiopathic macular telangiectasia. Retina. 2008;28(6):808-816.

13. Charbel Issa P, Berendschot TT, Staurenghi G, Holz FG, Scholl HP. Confocal blue reflectance imaging in type 2 idiopathic macular telangiectasia. Invest Ophthalmol Vis Sci. 2008;49(3):1172-1177.

14. Charbel Issa P, van der Veen RL, Stijfs A, Holz FG, Scholl HP, Berendschot TT. Quantification of reduced macular pigment optical density in the central retina in macular telangiectasia type 2. Experimental eye research. 2009;89(1):25-31.

15. Powner MB, Gillies MC, Tretiach M, et al. Perifoveal muller cell depletion in a case of macular telangiectasia type 2. Ophthalmology. 2010;117(12):2407-2416.

16. Brown PK, Wald G. Visual Pigments in Human and Monkey Retinas. Nature. 1963;200:37-43.

17. Stringham JM, Hammond BR. Macular pigment and visual performance under glare conditions. Optom Vis Sci. 2008;85(2):82-88.

18. Loughman J, Akkali MC, Beatty S, et al. The relationship between macular pigment and visual performance. Vision Res. 2010;50(13):1249-1256.

19. Khachik F, Bernstein PS, Garland DL. Identification of lutein and zeaxanthin oxidation products in human and monkey retinas. Invest Ophthalmol Vis Sci. 1997;38(9):1802-1811.

20. Beatty S, Boulton M, Henson D, Koh HH, Murray IJ. Macular pigment and age related macular degeneration. Br J Ophthalmol. 1999;83(7):867-877.

21. Li B, Ahmed F, Bernstein PS. Studies on the singlet oxygen scavenging mechanism of human macular pigment. Arch Biochem Biophys. 2010;504(1):56-60.

22. Zeimer MB, Kromer I, Spital G, Lommatzsch A, Pauleikhoff D. Macular telangiectasia: patterns of distribution of macular pigment and response to supplementation. Retina.

2010;30(8):1282-1293. 
23. Zeimer MB, Spital G, Heimes B, Lommatzsch A, Pauleikhoff D. Macular telangiectasia-changes in macular pigment optical density during a 5 -year follow-up. Retina. 2014;34(5):920-928.

24. Clemons TE, Gillies MC, Chew EY, et al. Baseline characteristics of participants in the natural history study of macular telangiectasia (MacTel) MacTel Project Report No. 2. Ophthalmic Epidemiol. 2010;17(1):66-73.

25. Rohrschneider K, Springer C, Bultmann S, Volcker HE. Microperimetry--comparison between the micro perimeter 1 and scanning laser ophthalmoscope--fundus perimetry. Am J Ophthalmol. 2005;139(1):125-134.

26. Chen FK, Patel PJ, Xing W, et al. Test-retest variability of microperimetry using the Nidek MP1 in patients with macular disease. Invest Ophthalmol Vis Sci. 2009;50(7):3464-3472.

27. Trieschmann M, Heimes B, Hense HW, Pauleikhoff D. Macular pigment optical density measurement in autofluorescence imaging: comparison of one- and two-wavelength methods. Graefes Arch Clin Exp Ophthalmol. 2006;244(12):1565-1574.

28. Powner MB, Gillies MC, Zhu M, Vevis K, Hunyor AP, Fruttiger M. Loss of Muller's cells and photoreceptors in macular telangiectasia type 2. Ophthalmology. 2013;120(11):2344-2352.

29. Tout S, Chan-Ling T, Hollander $\mathrm{H}$, Stone J. The role of Muller cells in the formation of the blood-retinal barrier. Neuroscience. 1993;55(1):291-301.

30. Bringmann A, Pannicke T, Grosche J, et al. Muller cells in the healthy and diseased retina. Prog Retin Eye Res. 2006;25(4):397-424.

31. Newman E, Reichenbach A. The Muller cell: a functional element of the retina. Trends Neurosci. 1996;19(8):307-312.

32. Higgs MH, Romano C, Lukasiewicz PD. Presynaptic effects of group III metabotropic glutamate receptors on excitatory synaptic transmission in the retina. Neuroscience. 2002;115(1):163-172.

33. Matsui K, Hosoi N, Tachibana M. Active role of glutamate uptake in the synaptic transmission from retinal nonspiking neurons. J Neurosci. 1999;19(16):6755-6766.

34. Zeimer M, Dietzel M, Hense HW, Heimes B, Austermann U, Pauleikhoff D. Profiles of macular pigment optical density and their changes following supplemental lutein and zeaxanthin: new results from the LUNA study. Invest Ophthalmol Vis Sci. 2012;53(8):4852-4859.

35. Choi RY, Gorusupudi A, Wegner K, Sharifzadeh M, Gellermann W, Bernstein PS. Macular Pigment Distribution Responses to High-Dose Zeaxanthin Supplementation in Patients with Macular Telangiectasia Type 2. Retina. 2017;37(12):2238-2247.

36. Zeimer MB, Padge B, Heimes B, Pauleikhoff D. Idiopathic macular telangiectasia type 2: distribution of macular pigment and functional investigations. Retina. 2010;30(4):586-595. 
Müller et al.: Macular pigment and disease progression in MacTel type 2

\section{Figure captions}

Figure1: Classification of MPOD distribution patterns according to Zeimer et al. ${ }^{22}$ Class 1 is defined as a wedge-shaped loss of macular pigment that is restricted to the temporal parafovea. In class 2, this area is enlarged, and the foveal pigment is reduced. Class 3 is characterized as a central loss of macular pigment within an oval shaped area that is centered on the foveola, and with or without residual pigment that is located circularly at $5^{\circ}$ to $7^{\circ}$ eccentricity.

Figure 2: Loss of ellipsoid zone is limited to the area of reduced MPOD in MacTel type 2. Exemplary courses of three eyes with MPOD classes 1-3 at baseline (BL), and follow up (FU) are shown. Red outline: area of MPOD reduction/ loss. Blue outline: ellipsoid zone loss (en face).

Figure 3: In microperimetry, scotomata are limited to the area of reduced MPOD in MacTel type 2. Exemplary courses of three eyes with MPOD classes 1-3 at baseline (BL) and follow up (FU) are shown. Red/ black border: area of MPOD reduction. Red test points represent absolute scotomata on microperimetry testing, yellow/ orange test points represent a relative reduction of sensitivity and green test points display a normal retinal sensitivity (for details see text).

Figure 4: Change of different outcome parameters after 60 months in relation to baseline. Functional loss (top left to bottom left) and morphological changes (bottom right) increase with MPOD classes. A significant decrease of visual acuity and reading acuity as well as a significant increase of scotoma size and EZ break is observed in eyes of MPOD classes 2 and 3 , while outcome parameters remain stable in eyes of class 1 .

$n=90$ eyes: MPOD class $1: n=18$; class 2 : $n=23$; class $3: n=49 ;{ }^{*} p<0.01 ;{ }^{* *} p<0.001$. 


\begin{tabular}{|l|r|r|r|r|r|r|}
\hline Subgroup & \multicolumn{2}{|l|}{ Class 1 } & \multicolumn{2}{l|}{ Class 2 } & \multicolumn{2}{l|}{ Class 3 } \\
Mean & \pm SD & Mean & I SD & \multicolumn{1}{|c|}{ Mean } & \pm SD \\
Number of eyes per & 18 & - & 23 & - & 49 & - \\
group & 0.02 & 0.07 & 0.14 & 0.19 & 0.28 & 0.18 \\
Visual acuity [logMAR] & 0.06 & 0.09 & 0.23 & 0.23 & 0.39 & 0.21 \\
Reading acuity [logRAD] & 0.4 & 1.2 & 2.6 & 2.5 & 7.2 & 6.3 \\
Scotoma size [tp] & 697 & 204 & 2282 & 364 & 18270 & 2833 \\
\hline
\end{tabular}

Table: Baseline characteristics of eyes of MPOD classes 1-3. 

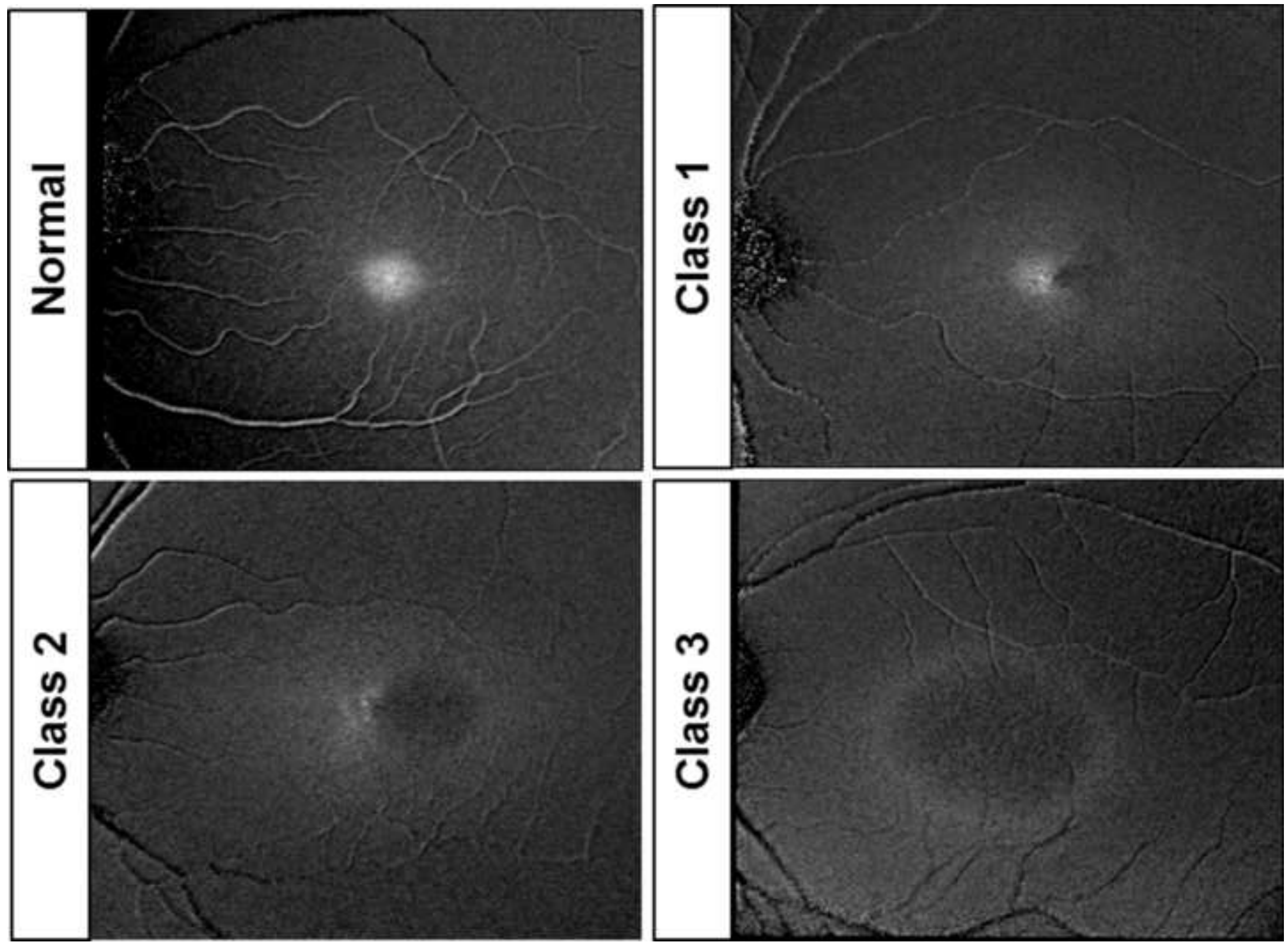
Figure 2
Click here to download high resolution image

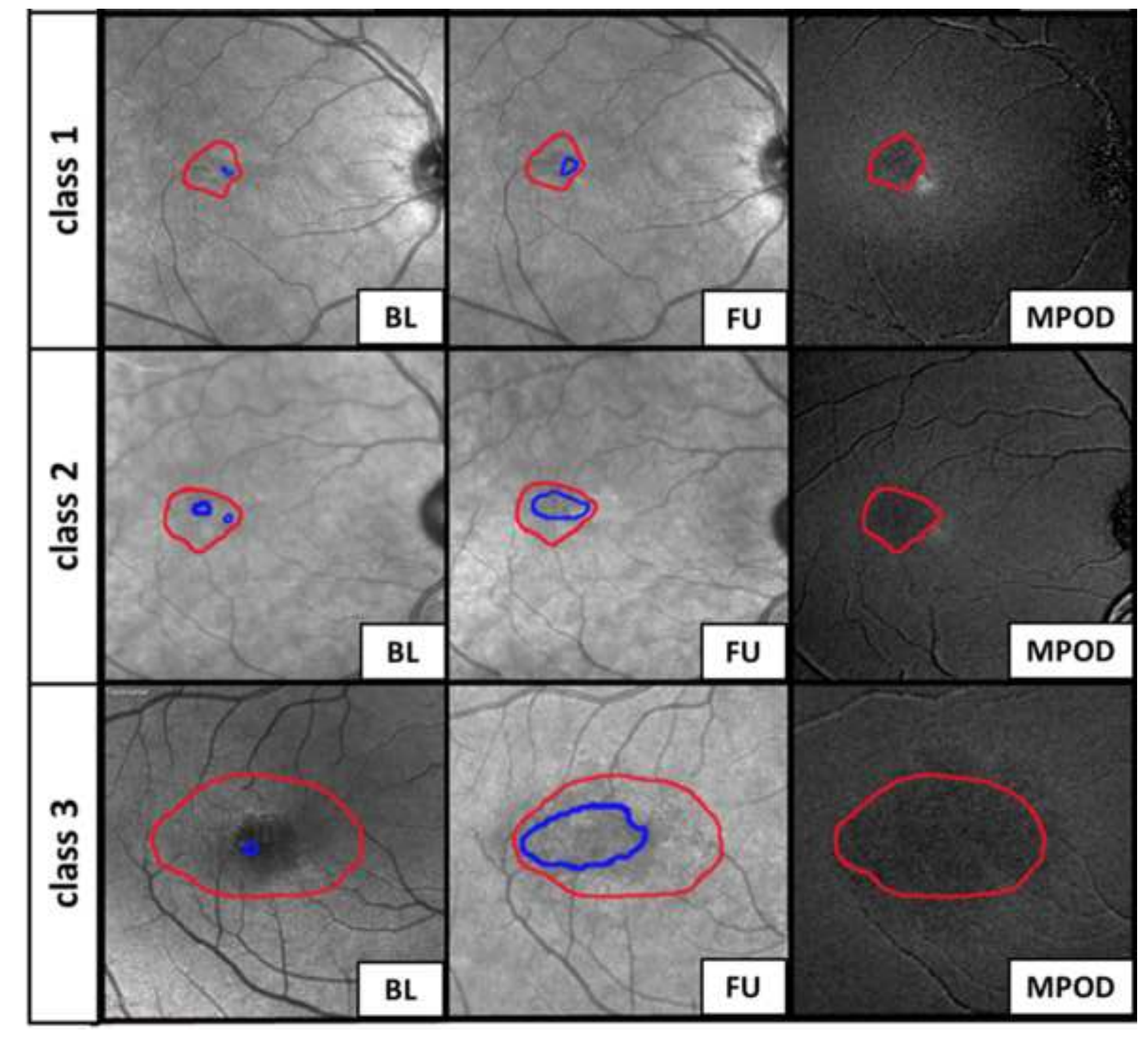




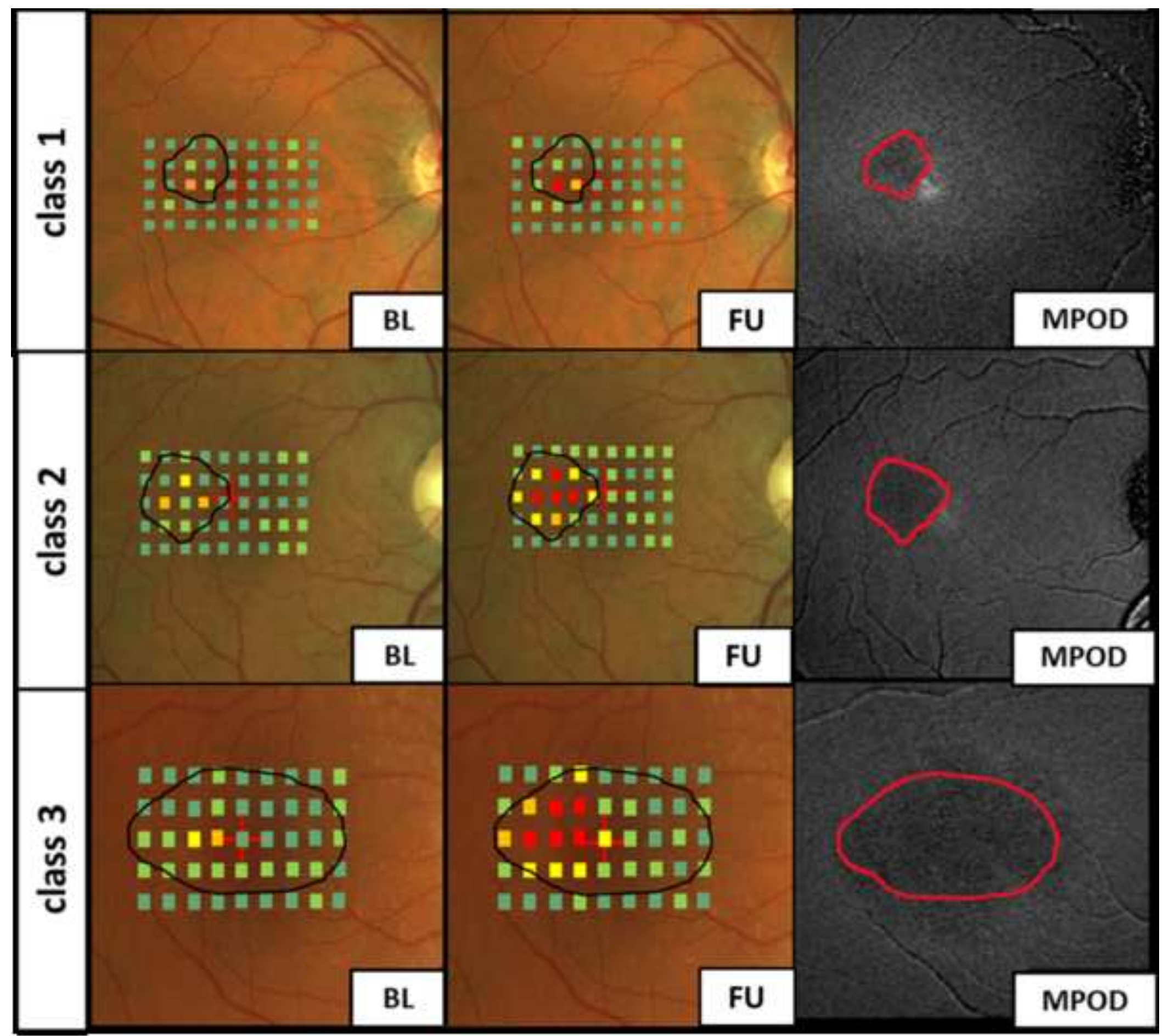

Figure 3
Click here to download high resolution image

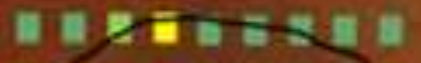

D. $\quad$ and

( $\quad$ 표 $n$ )

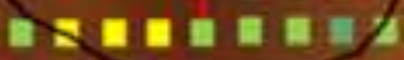

a $\mathrm{x}$ से 

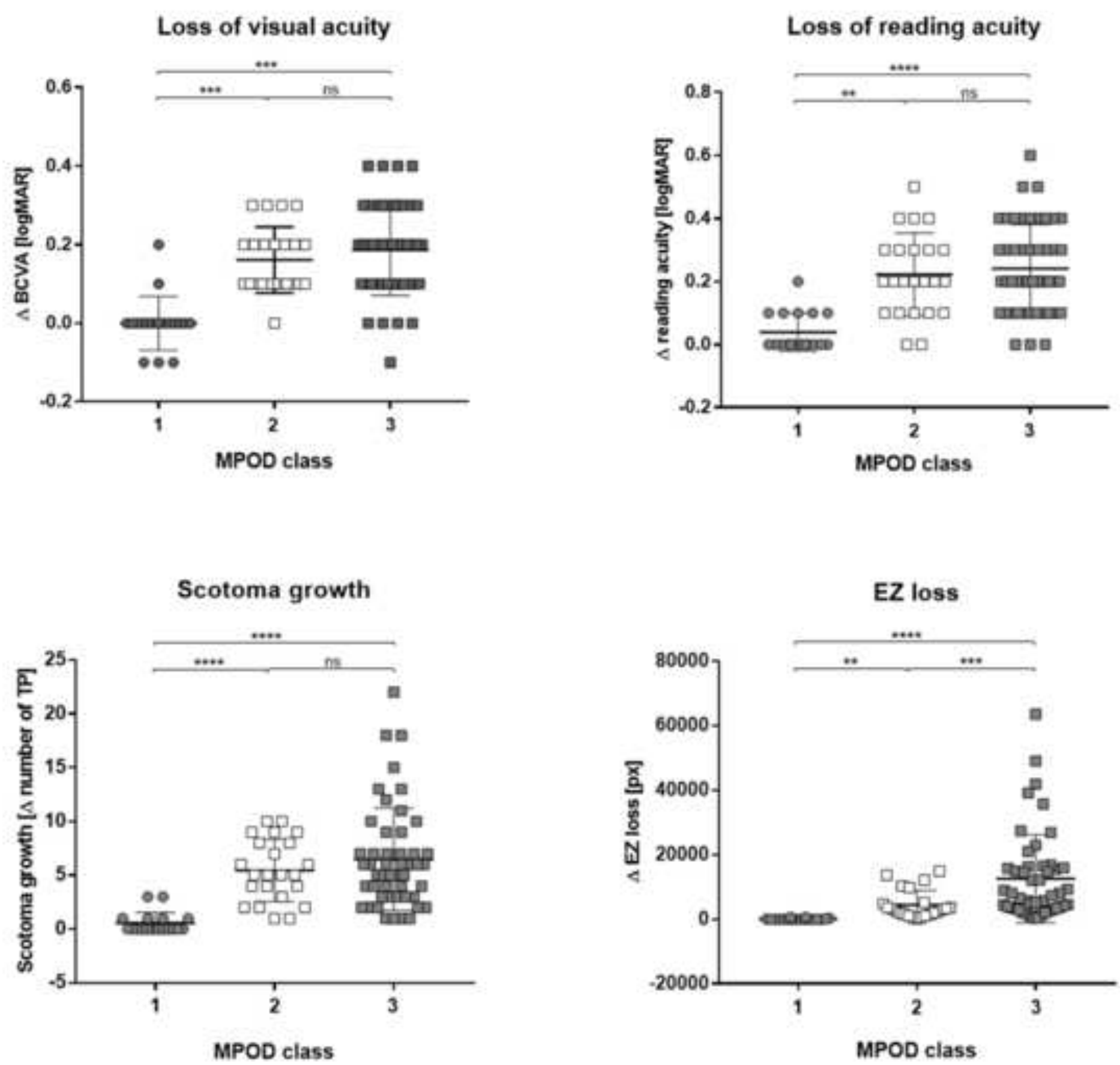
In this study, macular pigment (MP) and its pattern of distribution were longitudinally assessed in patients with macular telangiectasia type 2 (MacTel). Within an observational period of 60 months, functional (visual acuity, reading acuity, scotoma size) and morphologic (ellipsoid zone break in optical coherence tomography) outcome worsened with increasing loss of MP, while pigment distribution patterns remained stable. These findings suggest MP as a potential marker for disease progression and functional impairment in MacTel. 


\section{Appendix:}

\section{Supplemental material}

\section{Supplemental Figure 1}

Exemplary courses of different patterns of MPOD distribution (classes 1 to 3 ) at baseline (BL, left image) and after $60 \pm 4$ months (M, right image). Grading and qualitative image analysis revealed no switch between MPOD classes within the observational period of 60 months. 